\title{
Perspectives on the History of Bovine TB and the Role of Tuberculin in Bovine TB Eradication
}

\author{
Margaret Good and Anthony Duignan \\ Department of Agriculture, Fisheries and Food, Agriculture House, Kildare Street, Dublin 2, Ireland \\ Correspondence should be addressed to Margaret Good, margaret.good@agriculture.gov.ie
}

Received 14 January 2011; Accepted 16 February 2011

Academic Editor: Mitchell V. Palmer

Copyright ( $) 2011$ M. Good and A. Duignan. This is an open access article distributed under the Creative Commons Attribution License, which permits unrestricted use, distribution, and reproduction in any medium, provided the original work is properly cited.

\begin{abstract}
Tuberculosis remains a significant disease of animals and humans worldwide. Bovine tuberculosis is caused by Mycobacteria with an extremely wide host range and serious, although currently probably underdiagnosed, zoonotic potential. Where bovine tuberculosis controls are effective, human zoonotic TB, due to Mycobacterium bovis or M. caprae, is uncommon and clinical cases are infrequent in cattle. Therefore, the control and ultimate eradication of bovine tuberculosis is desirable. Tuberculin tests are the primary screening tool used in bovine eradication. The choice of tuberculin test is dependent on the environment in which it is to be used. Tuberculin potency is critical to test performance, and the accurate determination of potency is therefore particularly important. The design of a control or eradication programme should take into consideration the fundamental scientific knowledge, the epidemiological profile of disease, the experience of other eradication programmes, and the presence, in the same ecosystem, of maintenance hosts, in which infection is self-sustaining and which are capable of transmitting infection. A control or eradication programme will necessarily require modification as it progresses and must be under constant review to identify the optimal desirable goals, the efficacy of policy, and constraints to progress.
\end{abstract}

\section{Introduction}

All members of the closely related phylogenic grouping of Mycobacteria known collectively as the M. tuberculosis complex may cause tuberculosis in a range of species including man. Some members of this group are predominantly human (M. tuberculosis, M. africanum, M. canetti) or rodent pathogens (M. microti), whereas others have a wide host spectrum (M. bovis, M. caprae) $[1,2]$. Hewinson et al. recently expanded the "phylogenetic analysis of strains of the $M$. tuberculosis complex to include single nucleotide mutations and deletions of spoligotype units" and concluded that "this group of organisms might best be described as a series of host adapted ecotypes, each with a different host preference representing different niches" [3]. Originally $M$. caprae had been considered to be a subspecies of either M. tuberculosis or M. bovis; however, it is now apparent that phylogenetically it preceded M. bovis and it is only since the development of genotyping techniques allowing greater discrimination that its existence became apparent [2].

\section{Bovine Tuberculosis}

In cattle the most important causes of tuberculosis-bovine TB (bTB) - are M. bovis and M. caprae, both of which cause infectious disease that may result in significant productivity problems due to ill health $[2,4-6] . M$. bovis has one of the broadest host ranges of all known pathogens and has been diagnosed worldwide. O'Reilly and Daborn citing various authors list the species in which the disease has been reported as domesticated and feral cattle, goat, pig, sheep, horse, cat, dog, fennec fox, deer, bison, buffalo, badger, possum, hare, ferret, wild and feral pig, antelope, Arabian Oryx, camel, llama, alpaca, man, humans, and nonhuman primates [7]. M. bovis has also been detected in lion, hyena, kudu, baboon, leopard, cheetah, warthog and bushpig, elk, coyotes, meerkats, black rhinoceros, aoudad (Barbary sheep), and Lynx [8-14]. Tuberculosis due to M. bovis or M. caprae is a zoonotic disease with a complex epidemiological pattern which includes the transmission of infection within, and between, man, domestic animals, and wildlife. The 
occurrence of M. caprae has been reported in many European countries such as Austria, France, Germany, Hungary, Italy, Slovenia, and the Czech Republic but to date it has not been detected in Ireland (see [2], Department of Agriculture, Fisheries and Food (DAFF) records unpublished). Disease caused by $M$. caprae is not considered to be substantially different from that caused by $M$. bovis and the same tests can be used for its diagnosis [15].

\section{Zoonotic Implications}

It is estimated that $1.5-2 \mathrm{M}$ people die each year from tuberculosis of the approximately 2 billion infected persons worldwide [16]. M. bovis infection currently accounts for only a small percentage of reported cases but it was a major public health problem in Europe and elsewhere, when this organism was transmitted to man in milk from infected cows, prior to the advent of pasteurization of milk and milk products [7]. Thoen et al. and de la Rua-Domenech provide several reasons why $M$. bovis in humans is underdiagnosed even in developed countries [17, 18]. The consumption of unpasteurised milk or milk products still remains a risk for infection in countries where bTB has not been eradicated where ethnic populations present significantly different epidemiological profile or where HIV is prevalent [19-23]. Zoonotic TB was originally considered primarily as a disease of children where the disease involved the cervical lymph nodes (scrofula), the intestinal tract, or the meninges. It is now increasingly being recognised that infection in childhood is the precursor of reactivated adult disease and that many infected children may remain asymptomatic, undiagnosed, and untreated $[24,25]$. Thus zoonotic TB is of particular concern for developing countries, but where bTB controls are effective, human $M$. bovis or $M$. caprae isolates are uncommon and rare in countries where bTB has been eradicated $[2,16,18,22,26,27]$. M. bovis may affect humans of any age, and while the majority opinion is that humanto-human spread of $M$. bovis must be a very rare event, it does occur particularly amongst immunocompromised individuals [16, 25, 28-30]. O'Reilly and Daborn also referred to a small outbreak of tuberculosis in The Netherlands in 1994 caused by M. bovis which likely involved transmission from human to human [7]. The control and eradication of zoonotic TB requires the early recognition of preclinical infection in animals and the prompt removal of any infected animals in order to eliminate a future source of infection for other animals and for humans [31].

\section{Transmission of Infection}

O'Reilly and Daborn cite Sigurdsson who pre 1945, conducted experimental studies in laboratory animals which indicated that the size of the particles carrying the mycobacteria is of critical importance in determining infectivity [7]. This work also refers to the findings of research workers who, as early as the first decade of the 20th century, demonstrated that at least $10 \mathrm{mg}$ of bovine tubercle bacilli are necessary to cause alimentary infection in calves whereas $0.01 \mathrm{mg}$, a 1000 times smaller dose, produces an inhalation infection. Dean et al. demonstrated that $<10$ viable bacilli are sufficient to cause established tuberculosis pathology reflecting that seen in naturally infected field reactor cattle but they did not observe a dose-related effect in the pathology score up to 1,000 CFUs [32].

The respiratory route is accepted as the primary method of infection spread in all species. However, it is clear that there are other less common methods of spread such as oral, occupational, congenital and via wounds $[17,19,28,33-$ 37]. The postmortem evidence regarding the frequency of tuberculosis of the mammary glands in tuberculous cows appears to depend on the extent and duration of infection in the cow and is thus somewhat conflicting. Francis quotes incidences of $0.5-19.5 \%$ in tuberculous cows and $5-31 \%$ in cows with generalized tuberculosis [35]. Analysis of milk in countries with no bTB eradication programme continues to show similar levels of $M$. bovis detection [38, 39]. Even in countries with a bTB eradication programme where unpasteurised milk is routinely fed to calves on farm, a high prevalence of infection within those calves will indicate the probable presence of one or more cows with $M$. bovis in milk and require appropriate follow-up epidemiological investigation [19].

The transmission of $M$. bovis between cattle is dependent on a number of factors, including frequency of excretion, route of infection, the infective dose, the period of communicability, and host susceptibility. It is also possible that a range of highly specific conditions must occur for fine aerosols to be produced and for transmission to take place [40]. Transmission and observational studies suggest that the required conditions are unlikely to exist when a tuberculous animal is in the early stages of infection [40]. This view is also supported by studies conducted in cattle, which have indicated that bacterial shedding is, at best, transient and involves extremely low numbers of bacilli [41]. In man and badgers also the risk of transmission increases as disease progresses, and these species usually only become highly infectious when the disease is advanced and large numbers of organisms are being excreted [37, 42, 43]. Little et al. demonstrated transmission between naturally infected badgers and calves housed with them after a lapse of 6 months [44]. Field experience also indicates that cattle in the early stages of disease or with discrete walled-off lesions do not commonly transmit $M$. bovis to in-contact animals [40, 45-47]. On balance, the current evidence suggests that while some animals in the early stages of disease do excrete low numbers of $M$. bovis, in-contact animals do not readily acquire infection $[40,41]$.

4.1. Environmental Transmission. Various durations of environmental survival of $M$. bovis are reported in the literature depending on the conditions under which the research has been conducted. Early work suggested that M. bovis is a highly resistant organism surviving in cow faeces, for at least 5 months in winter, 4 months in autumn, 2 months in summer up to 2 years in soil; 4 months in liquid manure stored underground, and 1-2 months in soil during the 
summer months [48]. Despite the prevalence of clinically advanced cases of bovine tuberculosis at the time that they were conducting their studies, early 20th Century, Williams and Hoy comment on the great difficulty they experienced in finding animals with naturally infected faeces such that $76 \%$ of samples from known tuberculous cows gave negative results and the irregularity of positive results with naturally infected faeces led them to conduct their work with artificially infected faeces [48]. O'Reilly and Daborn also discuss where Maddock in 1935-1936 reported grazing paddocks, with naturally infected cows and artificially infected calves, so as to produce pastures with a heavier infection burden than would be likely to occur naturally [7]. When the infected animals were removed, tuberculosis-free calves grazed these pastures for a 3-week period following intervals of 1,2 , and 3 months. On subsequent tuberculin testing and postmortem examination, all the calves proved to be free from any evidence of tuberculosis. O'Reilly and Daborn also detail how Schellner in 1959 experimentally irrigated pasture plots with $10^{2}-10^{12} \mathrm{M}$. bovis per $\mathrm{ml}$ of water and after intervals of 7 , 14, and 21 days allowed 56 heifers to graze the plots [7]. Only 2 of 14 animals which grazed a plot irrigated 1 week previously became infected; all the others remained healthy. Little et al. failed to isolate $M$. bovis from a large number of environmental samples taken during and after a transmission study while in the same study badger faeces were positive for M. bovis [44]. Duffield and Young, working in North Queensland, were able to reisolate M. bovis from moist soil held in shade and darkness but not from any substrate held in sunlight or from faeces after 4 weeks [49]. They were not able to reisolate $M$. bovis from any substrate under any condition at or from 8 weeks. Thus, while M. bovis artificially deposited on soil or sterilised faeces stored away from sunlight may survive for several months, under natural conditions $M$. bovis appears to die out more quickly as in-contact animals do not readily acquire infection $[7,40,48,49]$.

4.2. Wildlife. Tuberculosis was described as a reemerging disease at the interface of domestic animals and wildlife by Palmer who cautioned that it will not be possible to eradicate M. bovis from livestock until transmission between wildlife and domestic animals is halted, and he advises that this will require a collaborative effort between stakeholders [50]. Corner has presented a detailed review of the role of wildlife as reservoirs of $M$. bovis differentiating between those that act as maintenance hosts or disease reservoirs and those that are spill-over or dead end hosts in which disease is not self-sustaining and which therefore do not maintain disease in an environment [51]. Some wildlife species, principally the badger in the United Kingdom and Ireland, the Australian possum in New Zealand (but not in Australia), and previously water buffalo in Australia, have been recognised as significant reservoirs of $M$. bovis with endemic self-maintaining infection in these species constituting a major obstacle to disease control programmes [52-54]. Wildlife infection is also an issue in other countries such as Canada, where M. bovis reservoirs in elk and deer cause occasional problems in livestock; Spain where M. bovis reservoirs in deer and in particular wild boar, pose a threat to Lynx an endangered species and South Africa where multiple species are infected in conservation areas $[8,12,55-$ 58]. In Australia, elimination of wild water buffalo and feral cattle from areas where infection was endemic was a major component of the eradication campaign [54, 59]. Postmortem surveillance, epidemiological risk assessment, and the implementation of strict cattle movement controls finally brought disease under control, and Australia is now bTB-free [52, 59]. New Zealand has similarly employed strict population control measures against infected possum populations, and very considerable progress has been made $[54,60]$. Countries where population control measures for infected wild populations must necessarily be limited, for example, badgers in the UK and Ireland where the badger is a protected species, have succeeded in reducing high incidence disease levels in cattle and maintaining them at relatively low levels by a sustained test and cull programme such that bTB is no longer a significant threat to humans. While the indications are that badgers can excrete mycobacteria from the respiratory, digestive, and urinary tract as well as in exudates from skin lesions transmission of M. bovis infection among badgers appears to be mainly by the respiratory route and, although there is an overall trend for increased prevalence with age, the acquisition of infection apparently occurs most frequently in young animals due to pseudovertical transmission from mother to cub [61].

4.3. Human to Cattle Transmission. Francis described how in Denmark and Sweden, towards the end of their respective successful bovine TB eradication programmes, there was concern about the risk posed to cattle herds from infected humans [33]. O'Reilly and Daborn state that transmission of $M$. bovis infection from humans to cattle is usually direct and by the respiratory route but that indirect spread via bedding and/or hay contaminated with urine from human renal excreters was reported by Huitema in 1969 in The Netherlands and by Schliesser in 1974 in Germany [7]. They provided details from Huitema as to how M. bovis infected humans were the source of infection in 50 cattle herds in the Netherlands where a total of 636 tuberculin reactor cattle were identified, of which 497 were confirmed postmortem as M. bovis infected and where 24 of $50 \mathrm{M}$. bovis infected patients had urogenital tuberculosis, the others mostly pulmonary tuberculosis. The patients with urogenital tuberculosis had infected 259 (41\%) of the reactor animals. Citing Schliesser they stated that, in Germany, M. bovis infection in cattle is rare but, when it occurs, man-to-cow transmission is a principal cause and where, in 1 study, 12 patients had infected 114 cattle in 16 different herds: 9 of the 12 had genitourinary tuberculosis and 1 such patient had infected 48 cattle in 4 different herds. In 1987 Grange and Collins stressed that man might be a continuing important source of disease in cattle in Ireland and that urinary tract disease may be a hidden source of infection, and they warned that many patients with renal tuberculosis, especially older patients, had clear radiographs and only vague symptoms [62]. Srivastava reported detection of M. tuberculosis in cattle 
and also from milk on some farms in North India raising suspicion that infection had spread from humans [39].

\section{Tuberculin Tests}

Having discovered the "Tubercle bacillus" in 1882 Koch went on, in 1890, to demonstrate the properties of a tuberculin he had developed. The possibility of using this tuberculin to test cattle in order to identify those with TB was very quickly recognised, and by 1891 cattle testing was operating extensively [35]. Almost it would seem simultaneously the possibility of using tuberculin and tuberculin tests as a tool to eradicate bTB was also recognised. Bovine tuberculosis had become a problem that was exacerbated by the gradual intensification of cattle production in the postindustrial revolution era [35]. In the late 19th and early 20th Century it appeared that the generally infectious nature of the "Tubercle bacillus" and then also the zoonotic implications of bTB were not well appreciated. Thus it would appear that the motivation for control of bTB during this time was predominantly economic [35]. Even today in many countries or regions the adoption or not of a bTB eradication programme may depend on economic factors as there are often many other conflicting demands for scare resources. Hence, while many underdeveloped countries have problems with $\mathrm{TB}$ in cattle and at least some, also in wildlife, not all have or can afford compulsory or comprehensive bTB control programmes.

Finland was the first country, in the late 1890s, to commence a successful bTB eradication programme [35]. It was relatively quickly established that bTB could be eradicated by the use of tuberculin tests when these were used with knowledge of the strengths and limitations of the test being used. Once a test and removal programme was commenced for bovines, the incidence of clinical cases of bTB rapidly declined as infected animals were removed from the population. Thus, economic losses due to bTB declined simultaneously as the cattle population became healthier. Buxton and Glover describe how Moussu and Mantoux in 1908 elaborated the value of the intradermal tuberculin test when they described the type of response it elicited in tuberculous and nontuberculous animals [63]. By 1910 Finland was already using the, then new, intradermal test in their eradication programme. Other countries gradually also commenced eradication programmes as various tuberculin test methodologies were developed and refined. Richie, describing a number of the different methods of tuberculin testing employed, speaks of the subcutaneous test which depended on temperature records over time, a short thermal test, the ophthalmic and palpebral tests, the double intradermal test, the Stormont test, and the vulval test, all now discarded from general use [64]. Christiansen and Stubb are cited by Buxton and Glover as having, in 1910, selected the side of the neck as the site for injection of tuberculin because it gave the most consistent results regarding the presence or absence of tuberculosis infection in cattle [63]. Baisden et al. in 1951 confirmed the greater sensitivity of the neck over the caudal fold and that the neck is the most sensitive site [65]. Paterson detailed how sensitivity is greater in sites on the neck nearer the head and diminishes in sites near the shoulder and in those adjacent to the nuchal crest, and he recommended that injection should therefore be in the middle third of the neck [66]. The relative sensitivities of the different parts of the neck were confirmed by Good et al. [67]. Paterson also detailed how the test is interpreted primarily on a herd basis, taking into consideration the history of the herd but with sometimes difficulties arising in dealing with an individual animal [66]. Tuberculin testing of cattle has in many areas succeeded in eradicating bTB, and there is no doubt that where the disease was confined only to cattle a test and cull programme would succeed.

Tuberculin tests, which avail of a cell-mediated response to Mycobacteria, have now been used for the diagnosis of tuberculosis and preclinical infection in man and animals for more than 100 years [68]. In humans asymptomatic and radiographically negative persons, with no history of BCG vaccination, who are positive to tuberculin test, are regarded as latently infected. Only approximately 5\% of infected humans develop clinical symptoms within a year of infection and $5-10 \%$ of latently infected persons go on to develop chronic progressive $\mathrm{TB}$ owing to reactivation during their lifetime [69]. In cattle tuberculin tests are based on detection of the specific immunological response following exposure to M. bovis or indeed M. caprae at some period previously. Following exposure infection will have occurred and either progressed or become quiescent under control by the animal whose response is based on the infective dose and its own inherent immune system.

Monaghan reviewed the most common tuberculin tests in use today, namely, the caudal fold test (CFT) and the Single intradermal test (SIT) which both use only bovine tuberculin PPD and the Single intradermal comparative tuberculin test (SICTT), which uses bovine and avian tuberculin PPD in combination [68]. The use of the word single in describing these tuberculin tests distinguishes them from the now obsolete double intradermal test, which regards the first injection of tuberculin as a "sensitising" injection. There are a number of national bTB eradication programmes in the Europe Union using either the SIT or SICTT where, when one or more animals in a herd show a positive response to the test, statutory controls are applied at herd level [70, 71]. Both the SIT and SICCT methodologies including test interpretation and test intervals are described in the EU trade Directive $64 / 432 / \mathrm{EEC}$ and also by the OIE $[15,72]$. The SICTT has been used extensively in the Irish bTB eradication programme and has proven to be a very safe means to test and screen the Irish cattle population [73]. The caudal fold test is widely used in the USA and New Zealand and was also used in Australia during their bovine TB eradication campaign. There are also other regions of the world where this is the routine test of choice with or without use of the SICTT before animal removal.

To assess the efficacy of a particular tuberculin test methodology various parameters such as the test sensitivity, specificity, and predictive value are evaluated for the environment, the level of disease in the population, and the conditions in which the test is performed [74]. If more 
than one type of test is available, the relative values of these appraisals will dictate which test may be most useful in particular situations in order to maximise the performance of the test. In 1959 Ritchie pointed out that it is vital to use a tuberculin of potency greater than that to which the majority of infected animals will respond [64]. The balance of evidence appears to favour the use of tuberculin of sufficient potency for the detection of tuberculosis in cattle for the eradication of the disease. In several countries, bovine tuberculin is considered to be of acceptable potency if its estimated potency guarantees per bovine dose at least $2000 \mathrm{IU}( \pm 25 \%)$ in cattle. Field trials have confirmed the scientific basis supporting this potency level [75]. In cattle with diminished allergic sensitivity, a higher dose of bovine tuberculin is needed, and, in national eradication campaigns, doses of up to 5000 IU are recommended [15]. The use of a highly potent bovine tuberculin increases the sensitivity of the test. However, test specificity is not only influenced by the purity, potency, and dosage of the tuberculin and strictness of interpretation of the response in the animal it is also influenced by sensitization of the animal. The choice of the SICCT, being a more specific test than the Single Intradermal test (SIT) or any other tuberculin test using bovine PPD alone, for the Irish and UK eradication programmes, was influenced by the abundance of nonspecific causes of sensitization. This choice was validated by Lesslie and Hebert and O'Reilly and MacClancy, in 1975, who found that $8-12 \%$ of apparently noninfected cattle in Ireland and the UK react positively to the SIT but not to the SICTT [74, 76]. While the single most important cause of sensitization is exposure to $M$. bovis, other pathogenic mycobacteria, for example, Mycobacterium paratuberculosis subsp. avium, and nonpathogenic environmental Mycobacteria such as $M$. hiberniae, are abundant in the Irish environment and cause nonspecific sensitisation to bovine tuberculin PPD [77, 78]. In the majority of cases the SICTT serves to differentiate between responses from exposure to $M$. bovis and other nonspecific Mycobacteria.

5.1. Tuberculin. In 1959 Paterson described tuberculin as the most important diagnostic agent in eradication schemes for tuberculosis and it remains so today [66]. The methods of preparation of tuberculin and the ways in which it has been applied to the diagnosis of tuberculosis date from Koch's original "tuberculin" preparation in 1890 when he initially thought he had discovered a cure for tuberculosis. Monaghan remarks on how quickly the principal advantages and problems associated with the use of tuberculin as a diagnostic test were, within a year of its first use, tabulated and the conclusion drawn by a committee at the University of Pennsylvania that "tuberculin is of value in the diagnosis of tuberculosis in cattle" [68]. For the purpose of testing animals modern-day tuberculin is a purified protein derivative (tuberculin PPD, bovine or avian) prepared from the heat-treated products of growth and lysis of $M$. bovis or M. avium (as appropriate) capable of revealing a delayed hypersensitivity in an animal sensitised to microorganisms of the same species. Administration of Tuberculin confers no protection to acquiring infection or from progression to clinical disease in an already infected animal. Buxton and Glover also credited Siebert et al. with developing the precipitation phase in the manufacture of PPD, in 1934, so as to ensure removal of high-molecular-weight proteins, which had previously been responsible for sensitisation of the subject following injection. PPD also eliminated many of the nonspecific features of the old tuberculin [63, 79]. Paterson, citing Seibert at al., claimed that the advantages of PPD lie in the use of a pure active principle, such that successive batches contain the same amount of protein, the process of preparation is reproducible from batch to batch, and the protein yield per batch constitutes a valuable control measure [79]. Production methods have largely been standardised and under EU Regulations Tuberculin PPD is a licensed product required to be manufactured under Good Manufacturing Practice conditions and to comply with the European Pharmacopoeia and thus also conform to OIE requirements $[15,72,80]$. The preparatory method ensures that PPD tuberculin consists of a mixture of small water-soluble protein molecules and this protein content can be helpful in the chemical standardisation of tuberculin [81]. The protein content of tuberculin, however, does not predict its biological activity and consequently Directive $64 / 432 / E E C$ as amended sets out the minimum requirement for tuberculin potency and requires that potency assays must be performed in guinea pigs where the response is compared to a reference standard $[72,81]$. Performance of the assay is described by the OIE [15].

However, while these routine assays are most reliable when carried out in tuberculous guinea pigs sensitised with living virulent $M$. bovis the guinea pig potency is not necessarily representative of the clinical potency in cattle $[66,82-84]$. Paterson recommends that guinea pigs be used for the control at preparation with occasional check assays in cattle but that if the type of tuberculin is changed or if a change in character is suspected that appeal must be to the assay in cattle [66]. Changes in manufacturing and production procedures may also result in fluctuations in tuberculin potency and there may also be considerable variability in potency between batches of tuberculin, including those produced in the same centre $[83,85,86]$. Tuberculin potency fluctuation was seen during 1990-1992 associated with Good Laboratory Practice adaptations and in 2000 associated with changes instigated as a consequence of EU requirements in relation to Transmissible Spongiform Encephalopathies (unpublished observationsDAFF records). Therefore, periodic validation of bovine PPD potency, on routine bovine tuberculin supply, in naturally infected tuberculous cattle is recommended [81, 85]. According to WHO Technical Report Series no. 745, potency testing should be performed in the animal species and under the conditions in which the tuberculins will be used in practice [87]. This means that bovine tuberculins should be assayed in naturally infected tuberculous cattle. As this requirement is difficult to accomplish, routine potency testing is conducted in guinea pigs. However, periodic testing in tuberculous cattle remains necessary, and standard preparations always require calibration in cattle. 
The frequency of testing in cattle can be reduced if it is certain that the standard preparations are representative of the routine issue tuberculins and that the production procedures guarantee consistency [15]. Notwithstanding the EU and OIE specifications there are tuberculins of lower potency available and care should be exercised in selecting tuberculin as its potency has a considerable impact on test performance $[15,67,72,81,88]$.

5.2. Test Limitations. In common with all tests and assays the tuberculin test is not perfect. As tuberculin eradication programmes advanced in different countries around the world field experience progressively showed that not all infected animals gave a good response to tuberculin. Examples of poor responders cited by Ritchie include anergic animals or those exhibiting reactions to both avian and mammalian tuberculin, those in advanced stage of disease, animals with confined infection notably in the udder, those with localised infection often in the lymphatic glands that has become inactive (latent), and periparturient cows [64]. He goes on to say that it is essential that the tuberculin be of sufficient potency to produce a reaction in the maximum number of infected animals and to use a tuberculin of potency greater than that to which the majority of infected animals will respond. He warns, however, that the highly potent tuberculin required to detect bovine infection tends to increase the frequency of reactions associated with crosssensitisations arising from other organisms such as the human and avian types (M. tuberculosis and M. avium, resp.) and other (nonpathogenic) mycobacteria. Crosssensitisation also appears to have caused problems during the Danish bTB eradication programme-Ritchie quoting Plum from 1937 and 1939 [64]. In 1962 Karlson reported that nonspecific responses to tuberculin were seen in all countries where eradication measures applied and that it was a widespread problem of a serious nature [89]. Karlson also reported that the sensitivity to mammalian tuberculin by cattle exposed to $M$. tuberculosis disappears when the human source of exposure is removed [89]. Rushford also reported that nonspecific responses were an issue using the single caudal fold tuberculin test in Australia [90]. Lamont in 1947 discussed at length the phenomenon of periparturient desensitisation and that instead the calf receiving the colostrums of an infected cow became passively sensitised for 4-6 weeks [79]. Lamont also postulated reasons why the test cannot succeed under certain circumstances namely that

(1) in a case of recent infection a response has had insufficient time to develop,

(2) postmortem finding of encapsulated lesions in testnegative animals may be because the response has disappeared due to lack of stimulation from repeated doses of mycobacterial antigens,

(3) lack of a positive response to tuberculin during "active" infection occurs particularly in advanced cases but that this desensitisation could be produced by injecting tuberculin [79].
While tuberculin tests are imperfect, they have been shown to be effective and they have succeeded in reducing the incidence of bTB and indeed many countries have succeeded in eradicating bovine TB with their use $[71,91]$. One can see from the rapid progress Ireland made in the initial 5 years of their compulsory programme how quickly a country can pass from having high disease incidence (animal incidence 17\%) to having a relatively low incidence (animal incidence $0.4 \%$ ) [52]. However, such problems as described above by both Ritchie and Lamont still exist and continue to be manifest in eradication programmes which employ tuberculin tests [64, 79]. Delayed hypersensitivity may not develop for a period of 3-6 weeks following infection. Thus, if a herd/animal is suspected to have been in contact very recently with infected animals, delaying testing should be considered in order to reduce the probability of false-negatives. As the sensitivity of the test is less than $100 \%$, it is unlikely that eradication of tuberculosis from a herd will be achieved with only a single tuberculin test [15].

Tuberculin test-negative animals are found, at slaughter, with evidence of encapsulated lesions confirmed as caused by $M$. bovis. Where there is no active infection ongoing in the herd from which the animal was sourced the infection appears to relate to exposure some time, even perhaps years, previously [45]. In other cases where there is ongoing infection in the herd of origin, it may well have been as a result of recrudescence of tuberculosis in a previously infected animal and there are still other herds with ongoing problems with TB infection where perhaps desensitization owing to successive short-interval skin tests may be a contributing factor (see $[45,92]$, DAF records unpublished).

With regard to desensitisation produced by the injection of tuberculin Buxton and Glover in 1939 cited Cuillé and Chelle (1935) as having demonstrated a progressive loss of skin response when several injections are made [63]. Coad et al. have confirmed that repeated SICTT led to increasing desensitisation at subsequent tests [92]. Paterson quoting Swindle et al. (1950) pointed out that full sensitivity at and for 2 to 3 inches $(5-7.5 \mathrm{~cm})$ around the tuberculin injection site is only recovered after 6-8 weeks [66]. Ritchie also spoke of the region immediately adjacent to the original inoculation that had in some but not all instances become desensitised with reactions less marked but that full sensitivity was regained by about the 6th week [64]. Doherty et al. and more recently Coad et al. have also confirmed this now well-recognised phenomenon $[92,93]$. Coad et al. caution that the period of desensitisation may be longer than previously thought and that successive short-interval skin tests will result in progressive desensitisation, which should be considered when faced with "inconclusive-reactor" skin test responses [92]. They further cautioned that the possibility of repeat testing resulting in false-negative test outcomes in infected cattle with indeterminate test responses also cannot be excluded.

As a management tool in eradication test interpretation is standard or more severe dependent on the history of the herd, the level of infection within a particular group of cattle, and the epidemiological assessment of the outbreak. As eradication progresses epidemiological investigation and 
data analysis become more important. In addition the use of ancillary tests, group removal, and/or full herd depopulation may also be required to accelerate eradication. Particularly towards the end of an eradication programme the response to the detection of an infected herd may be full-herd depopulation in order to ensure that no infected animals may remain. In countries with low incidence of bTB herd depopulation may be an effective response to a serious outbreak of bTB in a herd. Full-herd depopulation on the other hand is unlikely to be a significant part of the initial stages of an eradication programme in a high incidence country. To alleviate some of the problems experienced with tuberculin tests considerable research efforts have been deployed in the effort to develop blood based assays which could be used either to augment or perhaps eventually replace tuberculin testing in cattle [94-98]. Other than the Interferon- $\gamma$ assay, which is approved for use in the EU and by the OIE as an ancillary test for the purpose of identifying additional infected animals in known infected herds, the majority of such assays remain at the research and development stage $[72,94]$.

5.3. Development of Testing Policies. Among animal health professionals there has been ongoing discussion concerning the linkage between policy and science [99-101], for example "the Role of Science in Food Policy" discussions held in Brussels in October 2010 on the initiative of the Presidentin-Office of the Council of Agriculture Ministers, Sabine Laruelle, the Federal Public Service for Health, Food Chain Safety, and the Environment under the Belgian Presidency of the Council of the European Union. Adapting policy to reflect scientific knowledge as it becomes available is not new to the field of tuberculosis. Paterson refers to the wealth of information on the experimental and natural pathogenicity of mycobacteria in the reports of the Royal Commissions on tuberculosis dating from 1907, 1909, 1911, and 1913 [66]. Ritchie in the same 1959 publication referring to the eradication of tuberculosis is quite clear that the experience of other countries and publications in the scientific literature of the day was taken into account when designing the British eradication programme [64]. Thus the experience of the USA where as early as 1900 measures to prevent both entries of infected animals from Europe and disease spread within the States commenced and where infection was eliminated on a geographic basis formed the foundation for the British programme. Also considered were the programmes from Finland where tuberculosis was brought under State control in 1898, from Denmark, where an eradication plan was introduced in 1922, from The Netherlands, which commenced control in Friesland early in the 20th century, and from Canada, which introduced an accredited herd plan in 1919. The exchange of experience between countries went in both directions as evidenced when The Netherlands, in order to overcome the problem of nonspecific reactions to tuberculin occurring in tuberculosis-free areas, introduced a comparative skin test in 1950, adopting the English directives, which they later in turn modified [102]. In 2006 More and Good reviewed the scientific and policy advances in the tuberculosis eradication programme in Ireland over the previous 20 years [52]. Other authors have also described disease epidemiology in bovines and other species including wild-life reservoirs, disease surveillance, risk evaluation, and risk management during control and eradication programmes $[54,56,59,60]$.

\section{Discussion and Conclusion}

In countries with bTB eradication programmes, operating on a test and cull basis, incidence rapidly declines and clinical evidence of tuberculosis in cattle is seldom encountered because the intradermal tuberculin test enables presumptive diagnosis and elimination of infected animals during the preclinical stage. Prior to the adoption of national bTB eradication campaigns, however, clinical signs associated with tuberculosis in cattle, with associated economic impact, were commonly observed [15].

Research continues into test development particularly blood-based assays [94, 96, 98]. With a view to further reducing $\mathrm{TB}$ levels in cattle considerable research effort is being expended, in the UK and Ireland, on the development of a vaccine to protect badgers from $\mathrm{TB}$ and thus to reduce transmission both between badgers and from badgers to cattle $[91,103,104]$. The UK has also been exploring the efficacy of cattle vaccination. The possibility of developing genetic lines of cattle with higher resistance to infection with M. bovis without impacting negatively on other desirable genetic traits is an exciting prospect [105, 106]. Scientific advances will undoubtedly continue and these will be incorporated into bTB eradication or control programmes as appropriate. Other policy adaptations will result as a consequence of country or regional specific epidemiological studies and/or data analysis. Eradication programmes should also be continuously monitored for effectiveness, with a view to identifying and evaluating the constraints to progress and implementing necessary modifications to the programme as required.

Control and eradication of bTB is a desirable objective both from an animal health perspective and also because of zoonotic implications. National bTB eradication programmes have been or are still operated in many countries throughout the world. Some of the South American countries, many of which have had voluntary programmes for a number of years, are at this time considering implementation of national compulsory programmes. In other countries, particularly in the developing world, the issue is still being debated [38, 39]. Most Member States of the EU, having commenced bTB eradication programmes with a high disease incidence, are now recognised as officially TB free under the trading directive [72]. Difficulties remain however, in some EU member states which still run eradication programmes, notably Greece, Ireland, Spain, UK and to a lesser extent Italy and Portugal. Other EU countries have intermittent or localised problems with bovine tuberculosis and thus must maintain vigilance $[2,71,72]$.

Tuberculin tests remain the primary tool for eradication in the bovine, and the choice of which tuberculin test to 
use for primary screening is dependent on the prevalence of mycobacteria and other cross-sensitising agents in the local environment. Tuberculin potency is critical to test performance and thus in selecting a tuberculin supply particular care should be taken to evaluate the potency assays performed during the manufacturing process. The performance of independent potency checks on tuberculin is worthy of consideration particularly in the target species. When clinical cases are removed and test and cull programmes are in operation in-contact animals do not readily acquire infection. However, for effective control of bTB the disease must be addressed in all infected maintenance species in the same ecosystem. Consequently other species sharing the environment with cattle must be risk assessed to identify potential maintenance hosts, and where other species will constitute an impediment to final eradication of tuberculosis in the bovine appropriate control strategies should be developed and/or adapted taking into consideration the experience in other countries with similar problems. Human sources of infection must be considered during epidemiological investigation of outbreaks. Data collection and data and epidemiological analysis capability must be incorporated into control and eradication programmes so that progress and the constraints to progress may be evaluated. Lessons learned elsewhere during the operation of control and eradication programmes should be considered and incorporated as appropriate. Further scientific developments in the area of vaccine production and delivery and in genomics to breed increasingly disease-resistant livestock can be expected to further the goals of bovine TB eradication in the future.

\section{References}

[1] R. Brosch, S. V. Gordon, M. Marmiesse et al., "A new evolutionary scenario for the Mycobacterium tuberculosis complex," Proceedings of the National Academy of Sciences of the United States of America, vol. 99, no. 6, pp. 3684-3689, 2002.

[2] W. M. Prodinger, A. Brandstätter, L. Naumann et al., "Characterization of Mycobacterium caprae isolates from Europe by mycobacterial interspersed repetitive unit genotyping," Journal of Clinical Microbiology, vol. 43, no. 10, pp. 49844992, 2005.

[3] R. G. Hewinson, H. M. Vordermeier, N. H. Smith, and S. V. Gordon, "Recent advances in our knowledge of Mycobacterium bovis: a feeling for the organism," Veterinary Microbiology, vol. 112, no. 2-4, pp. 127-139, 2006.

[4] Z. Cvetnic, V. Katalinic-Jankovic, B. Sostaric et al., "Mycobacterium caprae in cattle and humans in Croatia," International Journal of Tuberculosis and Lung Disease, vol. 11, no. 6, pp. 652-658, 2007.

[5] M. T. Javed, A. Aranaz, L. de Juan et al., "Improvement of spoligotyping with additional spacer sequences for characterization of Mycobacterium bovis and M. caprae isolates from Spain," Tuberculosis, vol. 87, no. 5, pp. 437-445, 2007.

[6] E. L. Duarte, M. Domingos, A. Amado, and A. Botelho, "Spoligotype diversity of Mycobacterium bovis and Mycobacterium caprae animal isolates," Veterinary Microbiology, vol. 130, no. 3-4, pp. 415-421, 2008.
[7] L. M. O'Reilly and C. J. Daborn, “The epidemiology of Mycobacterium bovis infections in animals and man: a review," Tubercle and Lung Disease, vol. 76, supplement 1, pp. 1-46, 1995.

[8] A. L. Michel, M. L. Coetzee, D. F. Keet et al., "Molecular epidemiology of Mycobacterium bovis isolates from freeranging wildlife in South African game reserves," Veterinary Microbiology, vol. 133, no. 4, pp. 335-343, 2009.

[9] D. J. O’Brien, S. M. Schmitt, D. E. Berry et al., "Estimating the true prevalence of Mycobacterium bovis in free-ranging elk in Michigan," Journal of Wildlife Diseases, vol. 44, no. 4, pp. 802-810, 2008.

[10] K. C. VerCauteren, T. C. Atwood, T. J. DeLiberto et al., "Sentinel-based surveillance of coyotes to detect bovine tuberculosis, Michigan," Emerging Infectious Diseases, vol. 14, no. 12, pp. 1862-1869, 2008.

[11] J. A. Drewe, A. K. Foote, R. L. Sutcliffe, and G. P. Pearce, "Pathology of Mycobacterium bovis Infection in Wild Meerkats (Suricata suricatta)," Journal of Comparative Pathology, vol. 140, no. 1, pp. 12-24, 2009.

[12] I. W. Esple, T. M. Hlokwe, N. C. Van Gey Pittius et al., "Pulmonary infection due to Mycobacterium bovis in a black rhinoceros (Diceros bicomis minor) in South Africa," Journal of Wildlife Diseases, vol. 45, no. 4, pp. 1187-1193, 2009.

[13] M. G. Candela, E. Serrano, C. Martinez-Carrasco et al., "Coinfection is an important factor in epidemiological studies: the first serosurvey of the aoudad (Ammotragus lervia)," European Journal of Clinical Microbiology and Infectious Diseases, vol. 28, no. 5, pp. 481-489, 2009.

[14] J. Pérez, J. Calzada, L. León-Vizcaíno, M. J. Cubero, J. Velarde, and E. Mozos, "Tuberculosis in an Iberian lynx (Lynx pardina)," Veterinary Record, vol. 148, no. 13, pp. 414415, 2001.

[15] World Organisation for Animal Health (OIE), "Manual of Diagnostic Tests and Vaccines for Terrestrial Animals 2009. Chapter 2.4.7: Bovine tuberculosis adopted," May 2009, http: //www.oie.int/fileadmin/Home/eng/Health_standards/tahm/ 2.04.07_BOVINE_TB.pdf.

[16] P. A. LoBue, D. A. Enarson, and C. O. Thoen, "Tuberculosis in humans and animals: an overview," International Journal of Tuberculosis and Lung Disease, vol. 14, no. 9, pp. 1075-1078, 2010.

[17] C. Thoen, P. LoBue, and I. De Kantor, "The importance of Mycobacterium bovis as a zoonosis," Veterinary Microbiology, vol. 112, no. 2-4, pp. 339-345, 2006.

[18] R. De La Rua-Domenech, "Human Mycobacterium bovis infection in the United Kingdom: incidence, risks, control measures and review of the zoonotic aspects of bovine tuberculosis," Tuberculosis, vol. 86, no. 2, pp. 77-109, 2006.

[19] P. Doran, J. Carson, E. Costello, and S. J. More, "An outbreak of tuberculosis affecting cattle and people on an Irish dairy farm, following the consumption of raw milk," Irish Veterinary Journal, vol. 62, no. 6, pp. 390-397, 2009.

[20] M. C. Hlavsa, P. K. Moonan, L. S. Cowan et al., "Human tuberculosis due to Mycobacterium bovis in the United States, 1995-2005," Clinical Infectious Diseases, vol. 47, no. 2, pp. 168-175, 2008.

[21] I. N. De Kantor, P. A. LoBue, and C. O. Thoen, "Human tuberculosis caused by Mycobacterium bovis in the United States, Latin America and the Caribbean," International Journal of Tuberculosis and Lung Disease, vol. 14, no. 11, pp. 1369-1373, 2010. 
[22] O. Cosivi, J. M. Grange, C. J. Daborn et al., "Zoonotic tuberculosis due to Mycobacterium bovis in developing countries," Emerging Infectious Diseases, vol. 4, no. 1, pp. 59-70, 1998.

[23] R. Cicero, H. Olivera, A. Hernández-Solis, E. RamírezCasanova, and A. Escobar-Gutiérrez, "Frequency of Mycobacterium bovis as an etiologic agent in extrapulmonary tuberculosis in HIV-positive and -negative mexican patients," European Journal of Clinical Microbiology and Infectious Diseases, vol. 28, no. 5, pp. 455-460, 2009.

[24] Y. K. Amdekar, "Tuberculosis-persistent threat to human health," Indian Journal of Pediatrics, vol. 72, no. 4, pp. 333338, 2005.

[25] J. T. Evans, E. G. Smith, A. Banerjee et al., "Cluster of human tuberculosis caused by Mycobacterium bovis: evidence for person-to-person transmission in the UK," The Lancet, vol. 369, no. 9569, pp. 1270-1276, 2007.

[26] P. D. O. Davies, Clinical Tuberculosis, Chapman \& Hall, Boca Raton, Fla, USA, 1st edition, 1994.

[27] P. R. Ingram, P. Bremner, T. J. Inglis, R. J. Murray, and D. V. Cousins, "Zoonotic tuberculosis: on the decline," Communicable Diseases Intelligence, vol. 34 , no. 3, pp. 339341, 2010.

[28] J. K. Schönfeld, "Human-to-human spread of infection by $M$. bovis," Tubercle, vol. 63, no. 2, p. 143, 1982.

[29] S. Bilal, M. Iqbal, P. Murphy, and J. Power, "Human bovine tuberculosis-remains in the differential," Journal of Medical Microbiology, vol. 59, no. 11, pp. 1379-1382, 2010.

[30] S. Godreuil, E. Jeziorski, A. L. Bañuls, T. Fraisse, P. Van De Perre, and M. L. Boschiroli, "Intrafamilial cluster of pulmonary tuberculosis due to Mycobacterium bovis of the African 1 clonal complex," Journal of Clinical Microbiology, vol. 48, no. 12, pp. 4680-4683, 2010.

[31] FSAI, ZoonoticTuberculosis and Food Safety, Food Safety Authority of Ireland, Dublin, Ireland, 2nd edition, 2008.

[32] G. S. Dean, S. G. Rhodes, M. Coad et al., "Minimum infective dose of Mycobacterium bovis in cattle," Infection and Immunity, vol. 73, no. 10, pp. 6467-6471, 2005.

[33] J. Francis, Tuberculosis in Animals and Man: A Study in Comparative Pathology, Cassell \& Co. Ltd., London, UK, 1958.

[34] H. Posthaus, T. Bodmer, L. Alves et al., "Accidental infection of veterinary personnel with Mycobacterium tuberculosis at necropsy: a case study," Veterinary Microbiology, vol. 149, no. 3-4, pp. 374-380, 2011.

[35] J. Francis, Bovine Tuberculosis: Including a Contrast with Human Tuberculosis, Staples Press, London, UK, 1947.

[36] M. O. Ozyigit, S. Senturk, and A. Akkoc, "Suspected congenital generalised tuberculosis in a newborn calf," Veterinary Record, vol. 160, no. 9, pp. 307-308, 2007.

[37] A. Nolan and J. W. Wilesmith, "Tuberculosis in badgers (Meles meles)," Veterinary Microbiology, vol. 40, no. 1-2, pp. 179-191, 1994.

[38] V. C. Jha, Y. Morita, M. Dhakal et al., "Isolation of Mycobacterium spp. from milking buffaloes and cattle in Nepal," Journal of Veterinary Medical Science, vol. 69, no. 8, pp. 819-825, 2007.

[39] K. Srivastava, D. S. Chauhan, P. Gupta et al., "Isolation of Mycobacterium bovis \& M. tuberculosis from cattle of some farms in north India-possible relevance in human health," Indian Journal of Medical Research, vol. 128, no. 1, pp. 26-31, 2008.
[40] J. M. Griffin and L. A. Dolan, "The role of cattle-to-cattle transmission of Mycobacterium bovis in the epidemiology of tuberculosis in cattle in the Republic of Ireland: a review," Irish Veterinary Journal, vol. 48, pp. 228-234, 1995.

[41] T. McCorry, A. O. Whelan, M. D. Welsh et al., "Shedding of Mycobacterium bovis in the nasal mucus of cattle infected experimentally with tuberculosis by the intranasal and intratracheal routes," Veterinary Record, vol. 157, no. 20, pp. 613-618, 2005.

[42] D. Menzies, "Effect of Treatment on Contagiousness of Patients with Active Pulmonary Tuberculosis," Infection Control and Hospital Epidemiology, vol. 18, no. 8, pp. 582586, 1997.

[43] A. Rouillon, S. Perdrizet, and R. Parrot, "Transmission of tubercle bacilli: the effects of chemotherapy," Tubercle, vol. 57, no. 4, pp. 275-299, 1976.

[44] T. W. A. Little, P. F. Naylor, and J. W. Wilesmith, "Laboratory study of Mycobacterium bovis infection in badgers and calves," Veterinary Record, vol. 111, no. 24, pp. 550-557, 1982.

[45] F. J. Olea-Popelka, E. Costello, P. White et al., "Risk factors for disclosure of additional tuberculous cattle in attestedclear herds that had one animal with a confirmed lesion of tuberculosis at slaughter during 2003 in Ireland," Preventive Veterinary Medicine, vol. 85, no. 1-2, pp. 81-91, 2008.

[46] J. W. Wilesmith and D. R. Williams, "Tuberculosis lesions in reactor cows," The Veterinary record, vol. 119, no. 2, p. 51, 1986.

[47] M. A. Schoenbaum, B. H. Espe, and B. Behring, "Epidemic of bovine tuberculosis cases originating from an infected beef herd in Oklahoma, USA," Preventive Veterinary Medicine, vol. 13, no. 2, pp. 113-120, 1992.

[48] R. S. Williams and W. A. Hoy, "The Viability of Bovinus (Bovinus) on Pasture Land, in Stored Faeces and in Liquid Manure," Journal of Hygiene, vol. 30, pp. 413-419, 1930.

[49] B. J. Duffield and D. A. Young, "Survival of Mycobacterium bovis in defined environmental conditions," Veterinary Microbiology, vol. 10, no. 2, pp. 193-197, 1984.

[50] M. V. Palmer, "Tuberculosis: a reemerging disease at the interface of domestic animals and wildlife," Current Topics in Microbiology and Immunology, vol. 315, pp. 195-215, 2007.

[51] L. A. L. Corner, "The role of wild animal populations in the epidemiology of tuberculosis in domestic animals: how to assess the risk," Veterinary Microbiology, vol. 112, no. 2-4, pp. 303-312, 2006.

[52] S. J. More and M. Good, "The tuberculosis eradication programme in Ireland: a review of scientific and policy advances since 1988," Veterinary Microbiology, vol. 112, no. 2-4, pp. 239-251, 2006.

[53] A. I. Ward, J. Judge, and R. J. Delahay, "Farm husbandry and badger behaviour: opportunities to manage badger to cattle transmission of Mycobacterium bovis?" Preventive Veterinary Medicine, vol. 93, no. 1, pp. 2-10, 2010.

[54] N. E. Tweddle and P. Livingstone, "Bovine tuberculosis control and eradication programs in Australia and New Zealand," Veterinary Microbiology, vol. 40, no. 1-2, pp. 23-39, 1994.

[55] G. Wobeser, "Bovine Tuberculosis in Canadian wildlife: an updated history review article compte rendu," Canadian Veterinary Journal, vol. 50, no. 11, pp. 1169-1176, 2009.

[56] A. Parra, A. García, N. F. Inglis et al., "An epidemiological evaluation of Mycobacterium bovis infections in wild game animals of the Spanish Mediterranean ecosystem," Research in Veterinary Science, vol. 80, no. 2, pp. 140-146, 2006. 
[57] C. Gortázar, M. J. Torres, J. Vicente et al., "Bovine tuberculosis in Doñana Biosphere Reserve: the role of wild ungulates as disease reservoirs in the last Iberian lynx strongholds," PLoS ONE, vol. 3, no. 7, Article ID e2776, 2008.

[58] A. L. Michel, R. G. Bengis, D. F. Keet et al., "Wildlife tuberculosis in South African conservation areas: implications and challenges," Veterinary Microbiology, vol. 112, no. 2-4, pp. 91$100,2006$.

[59] B. Radunz, "Surveillance and risk management during the latter stages of eradication: experiences from Australia," Veterinary Microbiology, vol. 112, no. 2-4, pp. 283-290, 2006.

[60] T. J. Ryan, P. G. Livingstone, D. S.L. Ramsey et al., "Advances in understanding disease epidemiology and implications for control and eradication of tuberculosis in livestock: the experience from New Zealand," Veterinary Microbiology, vol. 112, pp. 211-219, 2006.

[61] R. M. Anderson and W. Trewhella, "Population dynamics of the badger (Meles meles) and the epidemiology of bovine tuberculosis (Mycobacterium bovis)," Philosophical Transactions of the Royal Society of London, vol. 310, no. 1145, pp. 327-381, 1985.

[62] J. M. Grange and C. H. Collins, "Bovine tubercle bacilli and disease in animals and man," Epidemiology and Infection, vol. 99, no. 2, pp. 221-234, 1987.

[63] J. B. Buxton and R. E. Glover, "Tuberculin tests in cattle," A.R.C. Report Series 4, Privy Council Agricultural Research Council, London, UK, 1939.

[64] J. N. Ritchie, "Tuberculois," in Diseases due to Bacteria, A. W. Stableforth and I. A. Galloway, Eds., vol. 2, pp. 713-744, Buterworths, London, UK, 1959.

[65] L. A. Baisden, A. Larsen, and T. H. Vardaman, "Relative sensitivity of different skin areas of cattle to intradermal tests," American Journal of Veterinary Research, vol. 12, no. 45, pp. 273-275, 1951.

[66] A. B. Paterson, "Tuberculois," in Diseases due to Bacteria, A. W. Stableforth and I. A. Galloway, Eds., vol. 2, pp. 671-687, Buterworths, London, UK, 1959.

[67] M. Good, T. A. Clegg, E. Costello, and S. J. More, "The comparative performance of the single intradermal test and the single intradermal comparative tuberculin test in Irish cattle, using tuberculin PPD combinations of differing potencies," The Veterinary Journal. In press.

[68] M. L. Monaghan, M. L. Doherty, J. D. Collins, J. F. Kazda, and P. J. Quinn, "The tuberculin test," Veterinary Microbiology, vol. 40, no. 1-2, pp. 111-124, 1994.

[69] R. J. North and YU. J. Jung, "Immunity to tuberculosis," Annual Review of Immunology, vol. 22, pp. 599-623, 2004.

[70] J. P. Caffrey, "Status of bovine tuberculosis eradication programmes in Europe," Veterinary Microbiology, vol. 40, no. 1-2, pp. 1-4, 1994.

[71] F. J. Reviriego Gordejo and J. P. Vermeersch, "Towards eradication of bovine tuberculosis in the European Union," Veterinary Microbiology, vol. 112, no. 2-4, pp. 101-109, 2006.

[72] European Commission, "Council Directive of 26 June 1964 on animal health problems affecting intra-Community trade in bovine animals and swine (64/432/EEC, with later amendments). Office for Official Publications of the European Communities, Consolidated legislation (CONSLEG)," 2009, http://eur-lex.europa.eu/LexUriServ/LexUriServ.do?uri= CONSLEG:1964L0432:20091218:EN:PDF.

[73] M. Good, I. Higgins, and P. Maher, "The tuberculin testa safe means to test a cattle population for bovine tuberculosis," Irish Veterinary Journal, vol. 60, no. 11, pp. 680-684, 2007.
[74] I. W. Lesslie and C. N. Hebert, "The use of dilute tuberculins for testing cattle," The British veterinary journal, vol. 121, no. 9, pp. 427-436, 1965.

[75] L. M. O’Reilly, "Field trials to determine a suitable injection dose of bovine PPD tuberculin for the diagnosis of bovine tuberculosis in naturally infected cattle," Developments in Biological Standardization, vol. 58, pp. 695-763, 1986.

[76] L. M. O'Reilly and B. N. MacClancy, "A comparison of the accuracy of a human and a bovine tuberculin PPD for testing cattle with a comparative cervical test," Irish Veterinary Journal, vol. 29, no. 4, pp. 63-70, 1975.

[77] L. M. O’Reilly and B. N. Mac Clancy, "Estimation of the sensitivity, specificity and predictive value of the intradermal tuberculin test," Irish Veterinary Journal, vol. 32, pp. 127-128, 1978.

[78] R. Cooney, J. Kazda, J. Quinn, B. Cook, K. Müller, and M. Monaghan, "Environmental mycobacteria in Ireland as a source of non-specific sensitisation to tuberculins," Irish Veterinary Journal, vol. 50, no. 6, pp. 370-373, 1997.

[79] H. G. Lamont, "Tuberculin testing," The Veterinary Record, vol. 59, no. 32, pp. 407-409, 1973.

[80] European Commission, "Directive of the European Parliament and of the Council, of 6 November 2001 on the Community code relating to veterinary medicinal products (2001/82/EC with later amendments). Office for Official Publications of the European Communities, Consolidated legislation (CONSLEG)," 2009, http://eur-lex.europa.eu/LexUriServ/LexUriServ.do?uri=CONSLEG:2001L0082:20090807 :EN:PDF.

[81] J. Haagsma and A. Eger, "Quality testing of tuberculins and its practical consequences for the diagnosis of bovine tuberculosis," in Proceedings of the 2nd International Conference on Animal Tuberculosis in Africa and the Middle-East, Rabat, Morocco, October 1995.

[82] I. Davidson, "Laboratory assay methods for bovine tuberculin PPD (report of the Expert Group on Veterinary Sera and Vaccines of the European Pharmacopoeia Commission)," Developments in Biological Standardization, vol. 58, pp. 607-616, 1986.

[83] R. Dobbelaer, L. M. O’Reilly, A. Genicot, and J. Haagsma, "The potency of bovine PPD tuberculins in guinea-pigs and in tuberculous cattle," Journal of Biological Standardization, vol. 11, no. 3, pp. 213-220, 1983.

[84] M. Good, T. A. Clegg, F. Murphy, and S. J. More, "The comparative performance of the single intradermalcomparative tuberculin test in Irish cattle, using tuberculin PPD combinations from different manufacturers," Veterinary Microbiology. In press.

[85] J. Haagsma, L. M. O’Reilly, R. Dobbelaer, and T. M. Murphy, "A comparison of the relative potencies of various bovine PPD tuberculins in naturally infected tuberculous cattle," Journal of Biological Standardization, vol. 10, no. 4, pp. 273284, 1982.

[86] J. Haagsma, "Potency testing of bovine tuberculins," Developments in Biological Standardization, vol. 58, pp. 689-694, 1986.

[87] World Health Organisation (WHO), "Requirements for biological substances no. 16, annex 1: requirements for tuberculins," Tech. Rep. 745, WHO, Geneva, Switzerland, 1987, http://whqlibdoc.who.int/trs/WHO_TRS_745.pdf.

[88] D. Bakker, A. Eger, J. Mcnair et al., "Comparison of commercially available PPDs: practical considerations for diagnosis and control of bovine tuberculosis," in Proceedings 
of the 4th International Conference on Mycobacterium bovis (poster), Dublin, Ireland, August 2005.

[89] A. G. Karlson, "Non-specific or cross-sensitivity reactions to tuberculin in cattle," in Advances in Veterinary Science, vol. 7, pp. 148-153, Academic Press, London, UK, 1962.

[90] B. H. Rushford, "Investigations into the problem of nonspecific reactors to the single caudal fold tuberculin test in Victorian dairy cattle," Australian Veterinary Journal, vol. 40, pp. 406-411, 1964.

[91] S. J. More, "What is needed to eradicate bovine tuberculosis successfully: an Ireland perspective," Veterinary Journal, vol. 180, no. 3, pp. 275-278, 2009.

[92] M. Coad, D. Clifford, S. G. Rhodes, R. G. Hewinson, H. M. Vordermeier, and A. O. Whelan, "Repeat tuberculin skin testing leads to desensitisation in naturally infected tuberculous cattle which is associated with elevated interleukin-10 and decreased interleukin-1 beta responses," Veterinary research, vol. 41, no. 2, p. 14, 2010.

[93] M. L. Doherty, M. L. Monaghan, H. F. Bassett, and P. J. Quinn, "Effect of a recent injection of purified protein derivative on diagnostic tests for tuberculosis in cattle infected with Mycobacterium bovis," Research in Veterinary Science, vol. 58, no. 3, pp. 217-221, 1995.

[94] E. Gormley, M. B. Doyle, T. Fitzsimons, K. McGill, and J. D. Collins, "Diagnosis of Mycobacterium bovis infection in cattle by use of the gamma-interferon (Bovigam) assay," Veterinary Microbiology, vol. 112, no. 2-4, pp. 171-179, 2006.

[95] M. Coad, S. H. Downs, P. A. Durr et al., "Blood-based assays to detect Mycobacterium bovis-infected cattle missed by tuberculin skin testing," Veterinary Record, vol. 162, no. 12, pp. 382-384, 2008.

[96] H. M. Vordermeier, A. Whelan, P. J. Cockle, L. Farrant, N. Palmer, and R. G. Hewinson, "Use of synthetic peptides derived from the antigens ESAT- 6 and CFP- 10 for differential diagnosis of bovine tuberculosis in cattle," Clinical and Diagnostic Laboratory Immunology, vol. 8, no. 3, pp. 571-578, 2001.

[97] J. M. Pollock, M. D. Welsh, and J. McNair, "Immune responses in bovine tuberculosis: towards new strategies for the diagnosis and control of disease," Veterinary Immunology and Immunopathology, vol. 108, no. 1-2, pp. 37-43, 2005.

[98] C. Whelan, E. Shuralev, G. O'Keeffe et al., "Multiplex immunoassay for serological diagnosis of Mycobacterium bovis infection in cattle," Clinical and Vaccine Immunology, vol. 15, no. 12, pp. 1834-1838, 2008.

[99] W. D. Hueston, "Science, politics and animal health policy: epidemiology in action," Preventive Veterinary Medicine, vol. 60, no. 1, pp. 3-12, 2003.

[100] L. King, "Impacting policy through science and education," Preventive Veterinary Medicine, vol. 62, no. 3, pp. 185-192, 2004.

[101] J. G. Greis and D. N. Wear, "Conducting science in the public eye," Journal of Forestry, vol. 100, no. 7, pp. 46-49, 2002.

[102] J. Haagsma, "Tuberculosis and tuberculin," in "Strictly Scientific and Practical Sense". A century of the Central Veterinary Institute in the Netherlands 1904-2004 , P. Verhoef, J. M. van Leeuwen, and P. H. Bool, Eds., Erasmus Publishing, Rotterdam, The Netherlands, 2007.

[103] L. A. L. Corner, E. Costello, S. Lesellier, D. O’Meara, and E. Gormley, "Vaccination of European badgers (Meles meles) with BCG by the subcutaneous and mucosal routes induces protective immunity against endobronchial challenge with Mycobacterium bovis," Tuberculosis, vol. 88, no. 6, pp. 601609, 2008.
[104] S. Lesellier, L. Corner, E. Costello et al., "Immunological responses and protective immunity in BCG vaccinated badgers following endobronchial infection with Mycobacterium bovis," Vaccine, vol. 27, no. 3, pp. 402-409, 2009.

[105] M. L. Bermingham, S. J. More, M. Good, A. R. Cromie, I. M. Higgins, and D. P. Berry, "Genetic correlations between measures of Mycobacterium bovis infection and economically important traits in Irish Holstein-Friesian dairy cows," Journal of Dairy Science, vol. 93, no. 11, pp. 5413-5422, 2010.

[106] S. Brotherstone, I. M. S. White, M. Coffey et al., "Evidence of genetic resistance of cattle to infection with Mycobacterium bovis," Journal of Dairy Science, vol. 93, no. 3, pp. 1234-1242, 2010. 

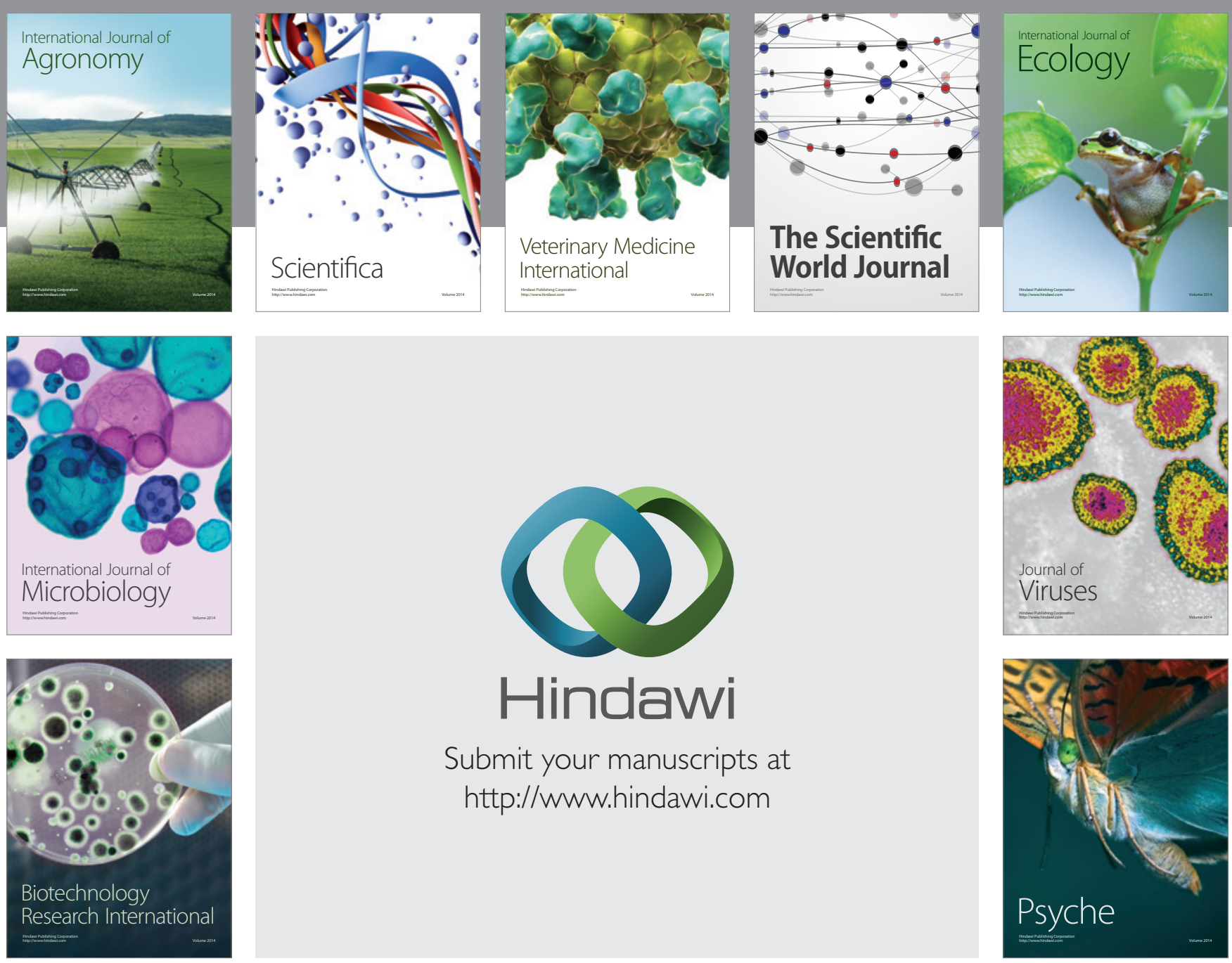

Submit your manuscripts at

http://www.hindawi.com
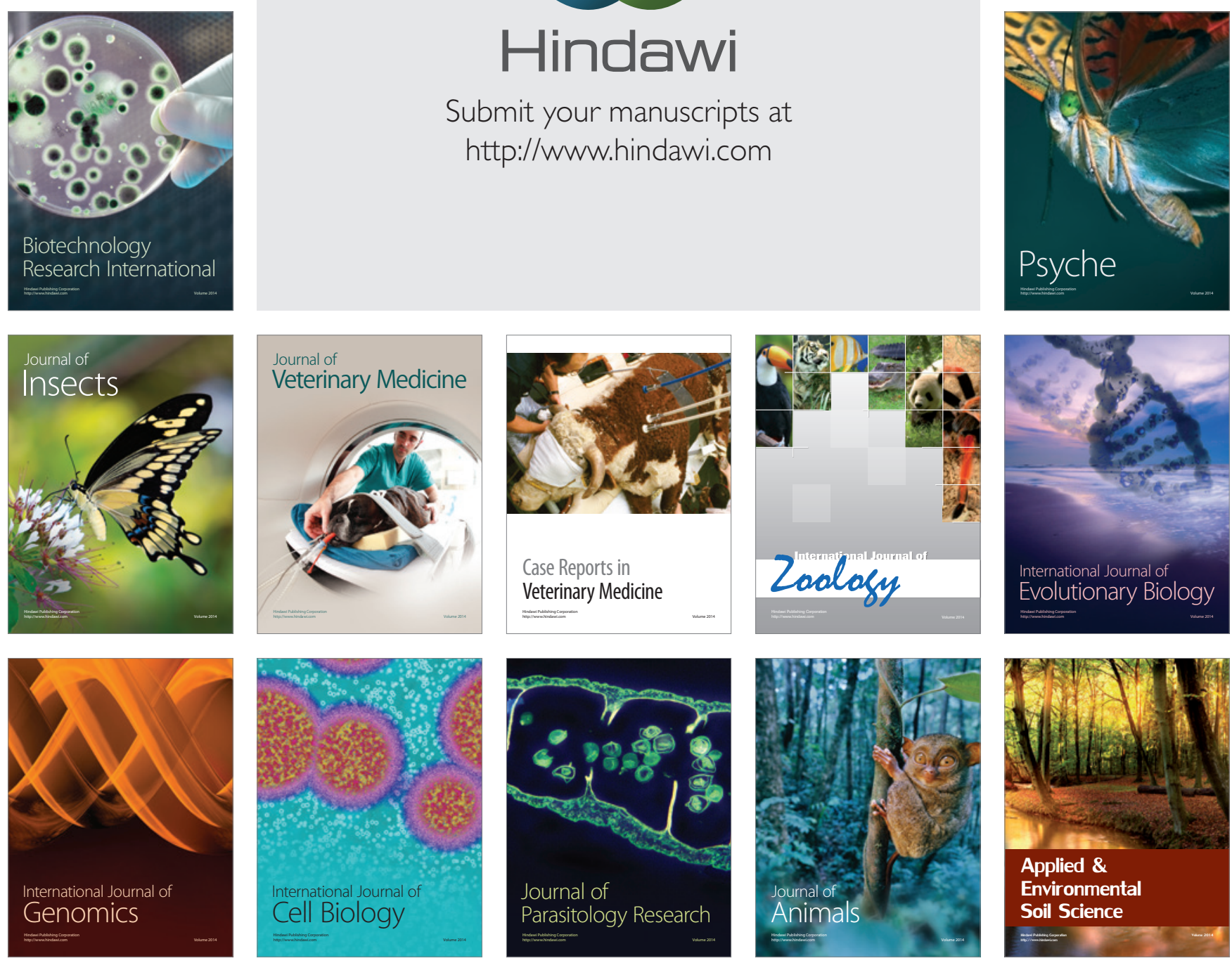